\title{
Image Analysis: Textile Industry in Indonesia
}

\author{
Hengky, S. H. \\ Director, SHINE Institute \\ Associate Professor, Triguna, School of Economics, Indonesia \\ Tel: 62-896-5704-5738_E-mail: hengky_halim@yahoo.com.au
}

Received: June 5, 2015

Accepted: June 23, 2015

Published: June 25, 2015

doi:10.5296/wjbm.v1i1.7883

URL: http://dx.doi.org/10.5296/wjbm.v1i1.7883

\begin{abstract}
In 2014, the Indonesian textile industry exports $36 \%$ of their woven fabric's amount USD 4.1 to the United States, $16 \%$ to the European Union and Japan, and 5\% to the Association of Southeast Asian Nations (ASEAN). This research was conducted from August 2014 to April 2015 in Indonesia. The questionnaires were distributed to 350 respondents, by using a stratified sampling, purposively, and triangulation techniques. The questionnaires were distributed to an international and national distributors, textile company staffs, textile agency, textile shopkeepers, tailor, staff of the garment, and the staffs of the Trade Minister of Indonesian. The image analysis shows that the woven fabrics of Indonesia are competitive. In terms of an image analysis, this study found three gaps of the image's expectation and performance. It is indicated that the plan of the Trade Minister of Indonesia would be done, as long as the plan is followed by increasing the production and finishing capacity of the textile industry, which were imported from several countries, such as Germany, Italy, and ASEAN country. They need the new technology of textile machine on getting a better quality and increasing the production capacity of the woven fabrics.
\end{abstract}

Keywords: Image analysis, Woven fabrics, Textile industry 


\section{Introduction}

According to the Minister of Industry of Indonesia, the textile industry exports are reaching $12^{\text {th }}$ textile world rank that contributes USD 12.6 billion in 2012 to USD 13.3 billion in 2014 . It fulfills $1.80 \%$ of the international demands of the textile products. In 2015, the Trading Minister of Indonesia, commands to the Indonesian Textile Association to prepare increasing their target production up to $5 \%$ of the common production. At the same time, the industry employed almost 1.5 million workers (API, 2013; Yogatama, 2014; and Thomasson, 2013). Responding the target, most of the textile industry increases their capacity by adding the number of a textile and finishing machine. They are importing 43.2 million Euros from Germany, and 34.2 million Euros from Italy.

In 2013, Indonesia exports $36 \%$ of their textile to the United States (USD 4.1 million), to the European Union and Japan $16 \%$, and to the Association of Southeast Asian Nations (ASEAN) $5 \%$ (Yogatama, 2014). At the same time, Indonesian textile and garment contribute $20 \%$ to the supply of an international garment and textile industry, which it amounts USD 7.52 million. Compared to Vietnam, their textile industry contributes USD 14.7 million, Turkey USD 24.29 million, Bangladesh - USD 19.95 million, and China USD 159.6 million (Umar, 2014).

The ASEAN trading role will be a good opportunity for Indonesian textile industry, because the trade barriers will be to reduce even be non-existent. This situation would increase export income, which in turn it would increase Indonesia's GDP. On the other hand, emerging new challenges of the Indonesian textile industry that would be a form of the commodities traded homogeneity and the problem of a supply chain of a yarn for a textile industry (Anwar, 2015; and Yogatama, 2014).

Indonesian economy in 2015 is projected to grow at about 5.8\%, said a Member of the House of Representatives Commission XI. He predicted the Indonesia's inflation in 2015 is much lower than in 2014. Inflation in 2015 is estimated to be in the range of 5\% because there is no increase in fuel prices. Meanwhile, in terms of a textile product, the Director of Commercial and Business Bank Mandiri said that by improving the economy, and a stronger exchange rate continue to be an opportunity to increase the export. Some commodity that can be exported is rubber, textiles and textile products (Anwar, 2015).

This research aim is to respond the future plan of the Trade Minister of Indonesia (API, 2013; Yogatama, 2014; and Thomasson, 2013) by using the image analysis of the woven fabrics of textile industry in Indonesia.

\section{Literature Review}

Bannister and Saunders (1978) analyzed the concept of a marketer's brand image by using image analysis, and consumer attitudes towards a particular product or brand in the domestic market and some countries, such as Britain, West Germany, Japan, France, Italy, United States, and the Soviet Union. They found that the concept of brand image and marketing strategies are effective is to use the development of individual marketing strategies. 
Image analysis also used to measure the properties of periodic and visual characteristics of woven fabrics, textile colors spatially in the digital image to identify the texture, fabric gradation, and translational and rotational symmetry image. This method proved to be useful in measuring piles textures and motifs (Wood, 1990).

Furthermore, image analysis is used to measure the power limitation of the landscape's fabric and into the image. The information showing that the morphology and equalization of the fabric spinning techniques useful in classifying the characterization and applications limit the power of landscape fabric (Xu, Pourdeyhimi, \& Sobus, 1992).

While, Zhang and Bresee (1995) analyzed the image colors, and motifs or designs woven fabric by using software of image analysis, which is based on two approaches: Detecting and classifying node; and Slub handicapped, by using the method of comparing the level of gray, woven, and twill fabrics.

At the same time, Na and Pourdeyhimi (1995) applied digital image processing on the degree of gradation of wrinkled fabric by using a combination of technique and texture profile analysis. The results showed that the wrinkling of fabric can be measured reliably using gray levels and surface statistic.

Nevertheless, in the three different image analysis techniques, the wavelet transform is used as tester's strength and quality fabrics with multi-resolution spectral filter. They could provide both shadowy and frequency of information on the fabric. For samples tested, wavelet transform can characterize fabric defects due to missing picks and ends faster and more accurate than other methods (Jasper \& Potlapalli, 1995).

Furthermore, Kang, Choi, Kim, and Oh (2001) developed structural analysis and quality of a woven fabric. In addition, by using the camera, they observed the fabric structure (construction of fabric, yarn crimp, the thickness of the fabric, and fabric weight per unit area), and drawing a cloth with the image processing and image analysis. The analysis showed the quality values woven fabric, disability clubs or picks that could be eliminated of an image.

Similarly, Escofet, Millán, and Rallo (2001) observed the fabric structure by using image analysis, which described the structure of a woven fabric and their use customized the minimum number of threads and yarns woven structure of a conventional weaving and its parameters are easily extracted into the fabric that expected.

At the same time, Sakaguchi, Wen, Matsumoto, Toriumi and Kim (2001) evaluated the quality and comparing a fabric surface, which was captured by an image scanner and human inspection, on the woven fabric by using image analysis. They found the peak width, containing the information of a fabric's surface quality.

Meanwhile, Liqing and Xiubao (2002) stated that the image analysis of woven fabric automatically could provide information, detection quality, and grading fabric from the textile production process. In addition, image analysis could also check the fabric quality included transformation wavelet defects that can be applied on an industrial scale. 
At the same time, Jensen and Carstensen (2002) evaluated the quality of a fabric by using digital image analysis using the backdrop of fluff and pills on textiles. The image analysis results evaluation of in accordance with the evaluation of the expert group of textiles. This evidence shows that it is reasonable to use the digital image analysis to evaluate the quality of knitted woven fabric.

In the same year, Xin, Hu, and Yan (2002) used the image analysis to extract the design's pill of the features of a clothes image, fabric-pilling evaluation, template matching pill, and they determine the reasonable limit of a histogram image of a segmentation fitting. There are five parameters that describe the amount of pills, as a nature-pill, pill region, the total area of pills, contrast and density of pills.

Earlier research from Rui-ling, Qing-Xiang, and Yu-he (2005) found that image analysis useful for aligning the quality of the image gradation or fabric's design, and it could improve the image's gradation by correcting it by using the gradation's manner after getting the evaluation from the reflection detector on the form of gradation image information and detection performance.

At the same time, Kim and Kang (2005) analyzed the image quality of the fabric by means of analyzing a segmentation pill (textile surface defects caused by wear and tear, and are considered unsightly), and using pills grading methods applicable for practical evaluation wavelet-based pilling and sub image.

Earliest study from Xin, Hu, and Baciu (2010) presented a digital imaging method based on image analysis on the surface profile silhouette with visualizing three-dimensional (3D) textile, and investigate the principles of 3-dimensional reconstruction. They used the method of testing the quality of the woven fabric with a non-destructive method for detecting surface characterization of fabric or material defects, reconstruct the third-dimensional surface profile, and discard unwanted information (e.g. The color of the woven surface).

A recent study from Ting (2015) explored the price aspect of the woven fabrics by image analysis, found that the price of textiles is influenced by the labor cost competitiveness of the textile industry. The study also showed that rising labor costs and labor productivity grew faster than the price of a fabric.

As mentioned above, from 1978-2010, this study elaborates a number of the research about an image analysis by using content analysis, found several attributes:

- $\quad$ Direction color (Zhang \& Bresee, 1995; and Wood, 1990);

- Designs cloth (Zhang \& Bresee, 1995; Xin, Hu, \& Yan, 2002; and Rui-ling, Qing-Xiang, \& Yu-he, 2005);

- $\quad$ Fabric texture (Na \& Pourdeyhimi, 1995);

- $\quad$ Fabric structure (Kang, Choi, Kim, \& Oh, 2001; Sakaguchi, Wen, Matsumoto, Toriumi \& Kim, 2001; Jensen \& Carstensen; 2002; and Escofet, Millán, \& Rallo, 2001); 
- Strength of textile products (Xu, Pourdeyhimi, \& Sobus, 1992; Kang, Choi, Kim, \& Oh, 2001; and Jasper \& Potlapalli, 1995);

- $\quad$ Price (Ting, 2015);

- Quality fabrics (Sakaguchi, Wen, Matsumoto, Toriumi \& Kim, 2001: Kim \& Kang, 2005; Xin, Hu \& Baciu, 2010; Jensen \& Carstensen, 2002; and Kang, Choi, Kim, \& Oh, 2001);

- $\quad$ Brand image (Bannister \& Saunders, 1978).

\section{Methodology}

The research was conducted from August 2014-April 2015 in Indonesia. The 350 respondents were collected purposive by stratified sampling and triangulation. The questionnaires were distributed to international and national textile distributors, textile company staffs, textile agency, textile shopkeepers, tailors, staffs of the garment, and the staffs of the Minister of Trading of Indonesian (Jenning, 2001).

The collected data was tabulated by the content analysis, which focus on image analysis (Cohen, 1960; and Gottschalk, 2013):

- $\quad$ Direction color (Zhang \& Bresee, 1995; and Wood, 1990);

- Designs cloth (Zhang \& Bresee, 1995; Xin, Hu, \& Yan, 2002; and Rui-ling, Qing-Xiang, \& Yu-he, 2005);

- $\quad$ Fabric texture (Na \& Pourdeyhimi, 1995);

- $\quad$ Fabric structure (Kang, Choi, Kim, \& Oh, 2001; Sakaguchi, Wen, Matsumoto, Toriumi \& Kim, 2001; Jensen \& Carstensen; 2002; and Escofet, Millán, \& Rallo, 2001);

- Strength of textile products (Xu, Pourdeyhimi, \& Sobus, 1992; Kang, Choi, Kim, \& Oh, 2001; and Jasper \& Potlapalli, 1995); Price (Ting, 2015);

- Quality fabrics (Sakaguchi, Wen, Matsumoto, Toriumi \& Kim, 2001: Kim \& Kang, 2005; Xin, Hu \& Baciu, 2010; Jensen \& Carstensen, 2002; and Kang, Choi, Kim, \& Oh, 2001);

- Brand image (Bannister \& Saunders, 1978).

The content analysis is tabulating of the actual image analysis, and the expectation of the image analysis: Posting each attribute of image analysis; Frequency of image analysis; Frequency count of image analysis; and closing with the discussions about the gap of the image analysis.

However, the existing image analysis is consistency obtained from the parameter of its attributes of Cohen's Kappa (K) (Landish \& Koch, 1997).

\section{Results and Discussions}

Based on the image analysis, which tabulated by content analysis (Table 1), the research found that the actual image of the woven fabrics is competence $(K=0.7486)$. Moreover, the direction color became the main point of its competence. 
Table 1. The result tabulation of the Actual Images of the woven fabric's Indonesia

\begin{tabular}{|l|c|c|}
\hline \multicolumn{1}{|c|}{ The Actual images of the woven fabrics' Indonesia } & Value & \% Freq \\
\hline Direction color & 42 & 0.1603 \\
\hline Designs cloth & 40 & 0.1527 \\
\hline Fabric texture & 35 & 0.1336 \\
\hline Fabric structure & 31 & 0.1183 \\
\hline Strength of textile products & 29 & 0.1107 \\
\hline Price & 28 & 0.1069 \\
\hline Quality fabrics & 30 & 0.1145 \\
\hline Brand image & 27 & 0.1031 \\
\hline
\end{tabular}

Note. Kappa Coefficient $=0.7486$ (Competitive, $\mathrm{K}>0.6)$.

Additionally, the woven fabric of Indonesia is competitive. It is not only the direction of color, but the design becomes the customer's second priority on choosing, buying and wearing it.

Notwithstanding, fabric texture becomes the third reason for the customer's decision to buy it. It seems that fabric structure also becomes the customer's priority, which influenced their decision on buying the woven fabrics. The rest, the competitiveness of the fabrics was supported by the structure, quality and the strength of a textile product as well.

\subsection{Direction Color}

Most of the woven fabric has a dominant color in accordance with fashion trends or seasons. The tendency toward the color woven fabric, always changing from time to time, and adapted to the development trends up to date. A direction of the color chosen by consumers at large depends on a needs and user activity. Both circumstances influenced the basis for their consideration to buy clothes that are tailored to a specific theme or event session.

Directions' color pale or tissue is a derivative of bright colors. Direction's color is a part of the cultural factors that generally was become for the target market of men's formal-shirts and lady-formal clothes using fabric for the market segment of the upper-middle class or sub-culture. These colors are widely used consumer living in the geographic area of the European, and the UK markets.

Moreover, the direction of the color of the wearer's also a cultural factor. It reflects the social level, and who have a certain social class. Directions pale color fabric / network suitable for market segment's career women that have formal activities, high-school students, the community, the middle and upper-middle class, and a career women or men customers. These market targets of the clothing market for consumers aged 20 to 50 years. In general, they are happy to wear that color direction, because it is dressed with a new kind of fabric models that are compatible with their lifestyles.

A cloth with bight colors in accordance with cultural factor's consumers to target markets and geographic region's Middle East (UAE), Africa, Malaysia, the Philippines, Colombo, and India. According to personal factors, a matching of the color direction for daily wear for several 
market's segments are using these materials, especially for a secondary export target market. In the context of positioning of a color direction is consistently to a bright-color. They were worn by a working women, high-school student, upper-class, upper-middle and the customer aged 10 to 40 years. Personnel factors of a consumer with lifestyle who want to look cheerful, was indicated by using a bright-color's suit. Most of them are more comfortable and confident when they wear clothing with the dominant bright-colors.

\subsection{Designs Cloth}

A design of the woven fabric was different for each target market. To understand the design's meaning of the textile, a company would select a pattern or motif, such as flower color, abstraction and stripes for a formal wear. Cultural and personal factors are very influential in the buying decision process along with its fabric design. The deciding factor is the culture and behavior of the fundamental desire, and the subculture of countries and specific geographic regions. In addition, several events also affect the design theme and become the factor design trends demand of the geographical area.

Favorites design of a target market of a Europe and America, like floral complete with stalk and leaves. While the direction of the current preferred color of them is a good soft color which dominant on a stem and leaves, but the direction of bright colors with flowers in soft colors is a personal positioning and target market of a cultural factor.

The geometric design and bright color become the target market of the Philippines, Malaysia, Colombo, and Africa market. They are very fond of the designs like circles, "contour," abstraction batik with "contour," and the design. This relates to the segment of the cultural, social and positioning of private consumers who greatly affect the basic design selection. Specifically to target the UAE market, Indonesia's export the textile to Jeddah has met market segments in the area. Because it showed that the value given by consumers in Jeddah against the design is quite significant.

\subsection{Fabric Texture}

On one hand, a softness textile product is very important, and it becomes the first terms of a customer decision-making process, because it is associated with thick or thicker of the cloth impression, quality, and more importantly is "falling from the fabric" on the body of the wearer. On the other hand, a certain market segment, the softness of the texture of a woven's surface to be value-added quality fabrics on maintaining consumer's positioning. Consumer perception is a major psychological factor that should be communicated to the consumer's personality. Because the softness of the fabric is closely related to the market segment of middle and upper economic classes, highly educated, and social class with a very specific lifestyle.

Moreover, the personal factors with the market segment liked the characteristic of age, occupation, economic circumstances, lifestyle and personality and self-concept, resulting in high need and demand for quality finishing soft cloth with unique textures into their yearning. Factors' subculture becomes the target market in some countries and geographical areas as an America and Europe markets have a need the quality fabric finishing, which does not affect 
for those who have more sensitive skin and allergy to chemicals during the process of finishing the fabric, and they are prioritizing the softness of fabric.

According to the results of the data tabulation and processing, fabrics, textures are becoming the first priority of a demand for American and European market segments. The consumer prefers a soft finishing and not allergic when strapped, and the color as the fabric is also resistant to the washing process with hot water. All were taken into consideration and agenda in the production process that should be a priority of the textile industry. Because it is the basis of a clause in the terms of quotas and export cloth in the country, and it has a significant value for the importing country.

Tabulated results indicate that the quality of softness and finishing of textile fabrics produced from the Indonesian state can meet the standard requirements within the country, and that means the quality of the texture and softness of fabrics to meet the needs of the target markets of America and Europe with a satisfactory value.

\subsection{Fabric Structure}

The Landscape and structure are determined by the laboratory elasticity of woven fabrics. Factor that affects the valuation of purchase is the strength in the softness of a fabric. One of the psychological factors that contribute learning involves changes in consumer behavior arising from the experience of buying textile products.

A positioning lifestyle of a consumer who has a social class that reflects it, and the education are becoming the deciding factor in choosing the type of fabric and its finish. The target market for this market segment is formed due to the fulfillment of their requests and needs. The consumer's position is forming a market share of textile products, because they bought and have a fabric with good strength. Another target of the export market is to meet their needs with repeat purchases, and at the same time they will be recommending and to be a potential reference for new customers.

Types of a fabric are divided on a consumers' viewpoint and the manufacturing process

\subsubsection{Woven Fabrics (Woven)}

Fabrics made from the crossing of two threads in the manner of a weaving. It is often called a fabric, and it consists of:

- Plain fabrics, woven fabrics with this fabric eventually in use, and it has a flat surface, because the fabric is patterned basket up and down between the thread, and the front and rear are looking the same.

- Woven fabric with this type has a higher power loss compared with woven fabrics, and low tear strength.

- Work wear fabric is most sometimes used to make shirts office, formal shirts, shirts daily uniforms, blazer, coat and other. 


\subsubsection{Woven fabric's Drill/Twill}

A drill has a surface cloth fabric visible lines diagonal lines. The fabric surfaces between the front and rear are different, the weave tighter and fabric is softer and wrinkle-resistant. In the manufacture of a drill work wear is more widely used for field shirts, mechanic's shirts, sales' T-shirt, various types of trousers, jacket and others.

\subsubsection{Woven Fabrics Satin}

This satin woven fabric surface is flat, smooth and shiny, because it can reflect light. It was developed by a tightly weaving and less powerful, because of its long float so easily broken if in drag, and low resilience rubbing. This type of fabric is the most often used for making dresses, upholstery/Croton, fabrics, and other home decoration.

\subsection{The Strength of a Textile's Product}

A factor that affects the valuation of purchase is the strength of a fabric. The strength of it includes tactile strength, and flexural strength.

The tractable strength of a fabric depends on a fabric and composite material matrix volume. Landscape fabric tensile strength is also determined by the volume of the fibers contained. The more fibers contained in the composite fabric will increase the mechanical strength to the fabric. Volume a fabric fiber is the same between volume and the volume metric.

A flexural-strength fabric is the largest bending stress, which can be received as a result of external loading without undergoing large deformation. The testing was conducted to determine the fabric resistance of a fabric to loading at a point of a bending and also to determine the elasticity of a fabric. The flexural strength testing of this fabric to give a loading perpendicular to the fabric samples with a three-point bending and dots as a particular barrier.

The model has a woven natural fiber yarn that had been made especially for clothing applications had a plain weave structure is relatively simple. To produce woven, which has a high mechanical strength is required models of different constructions with application clothing in general. This woven models specially designed to be able to withstand the load that is not damaged or failure of materials to a certain extent.

In addition, one of the psychological factors that play a role in the learning process of consumers, which involves a change in a consumer behavior, would lead to the experience of buying textile products. Buying experience better fabric strength, will lead to positive effects and motivate the consumer to purchase the product again on the same fabric.

However, the lifestyle of consumers who have a social class that reflects the position, education, consumer position, and when textile's products once purchased have an excellent strength. There will be repeat purchases and sales take place, even going to be the best reference. From the tabulation was indicated that the value of a qualitative attribute of a fabric strength became the better experience for the production manager in maintaining the quality of the finishing of a fabric. It showed by the results from the survey with the fairly 
good assessment (moderate).

\subsection{Price}

The price factor is closely related to personal factors and psychological factors. These factors lead to jobs that affect a consumption pattern. For the people of Europe and America that the majority of office workers, both men and women will buy work clothes with a fairly expensive price and would feel proud.

While, for a customer of a company's director, they will buy such expensive clothes depicting their position, and economic situation. The choice of products is strongly influenced by the conditions of society that consists of disposable income, savings, and debt. So that, the fabric was purchased, and it will be tailored to their finance ability. The UAE's community lifestyles are different from Jeddah community.

The prices through the location of the two countries are not so far away. The issue at a price for most of the UAE's society is quite critical. Another price case in the Jeddah's customer, regarding the price they can accept the quality of a fabric as the offering price. Given quality of a textiles / fabric on the offering are very good price. It is no longer an issue. Textile prices are set by the textile industry based on the yarn and a finishing quality of the woven fabrics. The price maker would attract the consumer, because it is quite competitive.

\subsection{Quality of Fabrics}

A quality to the textile fabric consists of four major sections: The quality to the raw material fabric (gray); The quality of printing or dying; Quality finishing fabrics; and the quality of the fabric inspection.

The quality of fabric is very dominant for export fabric quality. The quality of fabric is composed of a wide section of the fabric (called the weft) and long sections of fabric (called the warp). Defects in both directions of the fabric determine the grading fabric. For an export, quality only allowed two long rolls of fabric defect's fabric.

Quality fabric's printing is determined by the quality of a design and printing of fabric dyes. Similarly, the quality of dyed fabric is highly dependent on an absorb materials of a dyestuffs. The dying process is the means by which color is added to the textile material. Dying process can be applied in fibers, yarns, fabrics and shapes. Coloring is generally regarded as a single color for the uniform application of materials with a degree acceptable fade, or permanent.

Another way to apply a color on the fabric would be done by printing, which can produce a colorful pattern area on a fabric's surface. Printing process will be discussed in a separate module. Compounds on a dying process would be done by adding a color to textile materials which either dying or printing by using a pigment. Both types of compounds have very different properties and application procedures. Embed color dye penetration into the internal structure of the fiber at the molecular level, whereas the pigment attached to the outer surface of the fiber and held there by adhesive binder.

In addition, the quality of the finishing's is depending on the softness and thickness of the 
fabric. The fabric's softness can be produced from a good and the right of a.finishing process. A thickness of it was produced by weaving pattern on a fiber fabric and yarn weight per square meter.

However, grading fabrics in Indonesia have been adapted to the international standard of a fabric inspection. This is to meet the quota of textile exports prevailing market worldwide. Currently, the majority of consumers in the United States, Europe, and Japan have implemented the quality of it based on the environmental-friendly standards. This standard focuses on the materials that used during the manufacturing process based on the sustainable development. The results showed that the level of quality fabric in Indonesia meets international standards.

\subsection{Brand Image}

Brand image can be enhanced by improving the quality and production of communication by way of promotion. Brand image in various countries is highly dependent on the social, cultural, consumer behavior, and standardization or quota requirements. Both factors and consumer behavior are influenced by communal factors such as reference groups, family, and the role and status.

The success of communication indicated by the key factor of the campaign that can be accepted by community groups consisting of community reference, agency, or all groups. They have a direct or indirect influence over the attitudes or behavior within the community that will facilitate the marketing process.

To support the export of a textile product, marketing group functions would have a direct impact on a local community. It can be communicated it through the promotion, exhibitions abroad, which needed to be improved, or a can be directly promoted it by inviting a thematic reference group on how it is looked like to use textile products.

In addition, it also can be done through a psychological approach. Especially, when consumers want to purchase, used textile products from a certain brand, and through a learning process, including behavioral changes by arising from a positive experience. It is a kind of campaign with useful references.

The textile industry should try to communicate the quality of textile products and processes that based a concept of an environmentally friendly, especially to a consumer who did not respond to information. The results showed that an important attribute of a relevant information value is needed to be communicated to. This means that the fabric woven from Indonesia has been known by international markets of the America, Europe, United Arab Emirates, Germany, and the ASEAN countries. 
Table 2. The result tabulation of the Expectation Images of the woven fabric's Indonesia

\begin{tabular}{|l|c|l|}
\hline \multicolumn{1}{|c|}{ The Expectation images of the woven fabrics' Indonesia } & Value & \% Freq \\
\hline Direction color & 46 & 0.1475 \\
\hline Designs cloth & 43 & 0.1410 \\
\hline Fabric texture & 40 & 0.1311 \\
\hline Fabric structure & 37 & 0.1213 \\
\hline Strength of textile products & 33 & 0.1082 \\
\hline Price & 31 & 0.1016 \\
\hline Quality fabrics & 41 & 0.1344 \\
\hline Brand image & 35 & 0.1475 \\
\hline
\end{tabular}

Note. Kappa Coefficient $=0.8500$ (Competitive, $\mathrm{K}>0.6)$.

Table 3. The gap images of the woven fabric's Indonesia

\begin{tabular}{|l|c|c|c|}
\hline The gap images of the woven fabrics' Indonesia & Actual & Expectation & Gaps \\
\hline Direction color & 0.1603 & 0.1475 & -0.0128 \\
\hline Designs cloth & 0.1527 & 0.1410 & -0.0117 \\
\hline Fabric texture & 0.1336 & 0.1311 & -0.0024 \\
\hline Fabric structure & 0.1183 & 0.1213 & 0.0030 \\
\hline Strength of textile products & 0.1107 & 0.1082 & -0.0025 \\
\hline Price & 0.1069 & 0.1016 & -0.0052 \\
\hline Quality fabrics & 0.1145 & 0.1344 & 0.0199 \\
\hline Brand image & 0.1031 & 0.1475 & 0.0117 \\
\hline Kappa Coefficient's Gaps & 0.7486 & 0.8500 & $\mathbf{0 . 1 0 1 4}$ \\
\hline
\end{tabular}

Based on the tabulated results from the expected image analysis (Table 2), the study found that there are three gaps of the actual and expected of image analysis (Table 3). The gaps include: Gaps fabric structure, fabric quality and brand image. The rest had to meet market expectations.

Regarding the structure of the fabric and the fabric quality, the Association of Italian manufacturers of textile machinery, textile Indonesia has helped entrepreneurs by way of exporting its textile machinery and accessories to the country of Indonesia in 2012. They export these machines amounted to $€ 38$ million. With the increase of such machines is expected to increase production by $30 \%$ woven fabric of woven fabric production capacity installed in Indonesia.

In 2011, Indonesia imported finishing machine from the Italian state. And in 2012, the textile industry in Indonesia has increased its production by $35 \%$ of production capacity. Because in the first six months of 2013, all weaving machines imported that have accounted for an increase of $32 \%$ of the installed capacity of the textile industry. 
In the past four years, the production of woven fabric in Indonesia as a whole had increased production capacity by $30 \%$ woven fabric after their import of a textile machines and finishing from Italy (Thomasson, 2013).

This condition has helped businesses and governments woven fabric manufacturers to improve the fabric quality and the structure in the long term. Increased production capacity and the quality of a fabric will enhance the brand image of it. This can be an important involvement of the manufacturers of a fabric in the exhibition industry abroad through a fruitful program by collaborating with a commerce department.

\section{Conclusions and Implications}

Based on the actual and expected of image analysis of a consumer and stakeholders, the study found that the performance of woven fabrics from Indonesia is competitive. To be more aggressive, fabric producers should pay more attention to the three gaps that found through the gap image analysis. In detail, the three gaps are the structure of fabric, the quality to the fabric, and the brand image of the fabric.

By implication, this study shows that the plan of the Trade Minister of Indonesian would be done. To improve the quality of woven fabric and fabric structure, the producers of fabric can transform the old weaving machines by importing some modern weaving machines with machine finishing of some countries such as Germany, Italy, and the ASEAN countries, which supports better quality and increase production capacity woven fabrics (Anwar, 2015).

Meanwhile, to improve the brand image, the Trade Minister of Indonesia would help textile producers by improving communication intensively and facilitate the process of weaving and finishing machines. To motivate the producers, he could give tax holidays and invite them to collaborate actively in various worldwide exhibitions industries or even abroad.

The limitation this study, is a time and funding, Since this study is more on the textile production capacity in general. Therefore, it needs further study that examines more specific about the international marketing strategy

\section{Acknowledgements}

In this good chance, let me express my big thanks to the anonymous reviewer for their constructive comment to improve the final version of the paper. I would also like to thank to the Editors for their helpful and generous comments and support during the review processes.

\section{References}

Anwar. (2015). Islamic Banking Industry Facing Asean Economic Community (AEC) in 2015: Opportunities and Challenges of Contemporary. Depkeu.go.id. Retrieved from http://www.bppk.depkeu.go.id/publikasi/artikel/150-artikel-keuangan-umum/20434-industriperbankan-syariah-menghadapi-masyarakat-ekonomi-asean-mea-2015-peluang-dan-tantanga n-kontemporer

API. (2013). Roadmap for Indonesia's textile and textile products industry. Indonesian Textile Association.

Retrieved from 
http://www.indonesia-investments.com/news/todays-headlines/roadmap-for-indonesias-textil e-and-textile-products-industry/item673

Bannister, J. P., \& Saunders, J. A. (1978). UK Consumers' Attitudes towards Imports: The Measurement of National Stereotype Image. European Journal of Marketing, 12(8), 562-570. http://dx.doi.org/10.1108/EUM0000000004982

Cohen, J. (1960). A Coefficient of Agreement for Nominal Scales. Educational and Psychological, 20, 37-46. http://dx.doi.org/10.1177/001316446002000104

Escofet, J., Millán, M. S., \& Ralló, M. (2001). Modeling of woven fabric based on Fourier image analysis. Applied Optics, 40(34), 6170-6176. http://dx.doi.org/10.1364/AO.40.006170

Gottschalk, L. A. (2013). Content Analysis of Verbal Behaviour: New Findings and Clinical Applications. Routledge, 19-22.

Jasper, W. J., \& Potlapalli, H. (1995). Image Analysis of Mispicks in Woven Fabric. Textile Research Journal, 65(11), 683-692. http://dx.doi.org/10.1177/004051759506501109

Jenning, G. (2001). Tourism Research (pp. 136-152). John Willey \& Sons Australia, Ltd.

Jensen, K. L., \& Carstensen, M. (2002). Fuzz and Pills Evaluated on Knitted Textiles by Image Analysis. Textile Research Journal, 72(1), 34-50. http://dx.doi.org/10.1177/004051750207200107

Kang, T. J., Choi, S. H., Kim, S. M., \& Oh, K. W. (2001). Automatic Structure Analysis and Objective Evaluation of Woven Fabric Using Image Analysis. Textile Research Journal, 71(3), 261-270. http://dx.doi.org/10.1177/004051750107100312

Kim, S. C., \& Kang, T. J. (2005). Image Analysis of Standard Pilling Photographs Using Wavelet Reconstruction. Textile Research Journal, 75(12), 801-811. http://dx.doi.org/10.1177/0040517505059707

Landish, J. R., \& Koch, G. G. (1977). The measurement of observer agreement for categorical data. Biometrics, 33, 159-174. http://dx.doi.org/10.2307/2529310

Liqing, L., \& Xiubao, H. (2002). Recent Studies on Image-based Automatic Fabric Inspection System. Journal of Donghua University, Natural Science. Retrieved from http://en.cnki.com.cn/Article_en/CJFDTOTAL-DHDZ200204028.htm

Na, Y., \& Pourdeyhimi, B. (1995). Assessing Wrinkling Using Image Analysis and Replicate $\begin{array}{llll}\text { Standards. Textile } & \text { Research } & \text { Journal, } & 65(3),\end{array}$ http://dx.doi.org/10.1177/004051759506500303

Rui-ling, D., Qing-Xiang, L., \& Yu-he, L. (2005). Summary of image edge detection, Optical Technique. http://en.cnki.com.cn/Article_en/CJFDTOTAL-GXJS200503027.htm

Sakaguchi, A., Wen, G. H., Matsumoto, Y., Toriumi, K. \& Kim, H. (2001). Image Analysis of Woven Fabric Surface Irregularity. Textile Research Journal, 71(8), 666-671. 
http://dx.doi.org/10.1177/004051750107100803

Thomasson, S. C. (2013). Indonesia: Driving Ahead, Textile World Asia. Retrieved from http://www.textileworldasia.com/Issues/2013/October-November-December/Country_Profile s/Indonesia-Driving_Ahead

Ting, F. (2015). Impact of labor cost changes on the competitiveness of China's textile industry. International Journal of Economics, Commerce and Management, III(2), 1-8. Retrieved from http://ijecm.co.uk/ ISSN 23480386

Umar, I. S. (2014). 20\% of the national garment exports originating from batik. Asosiasi Pertekstilan Indonesia (API). Retrieved from http://apidki-jakarta.weebly.com/berita

Wood, E. J. (1990). Applying Fourier and Associated Transforms to Pattern Characterization in Textiles. Textile Research Journal, 60(4), 212-220. http://dx.doi.org/10.1177/004051759006000404

Xin, B., Hu, J., \& Baciu, G. (2010). Visualization of Textile Surface Roughness Based on Silhouette Image Analysis. Textile Research Journal, 80(2), 166-176. http://dx.doi.org/10.1177/0040517508093779

Xin, B., Hu, J., \& Yan, H. (2002). Objective Evaluation of Fabric Pilling Using Image Analysis Techniques. Textile Research Journal, 72(12), 1057-1064. http://dx.doi.org/10.1177/004051750207201204

Xu, B., Pourdeyhimi, B., \& Sobus, J. (1992). Characterizing Fiber Crimp by Image Analysis: Definitions, Algorithms, and Techniques. Textile Research Journal, 62(2), 73-80. http://dx.doi.org/10.1177/004051759206200203

Yogatama, B. K. (2014). Indonesia's textile industry to achieve the export target of the Rp 150.29 trillions. Tribunenews.com. Retrieved from http://www.tribunnews.com/bisnis/2014/04/14/industri-tekstil-indonesia-targetkan-ekspor-ca pai-rp15029-triliun

Zhang, Y. F., \& Bresee, R. R. (1995). Fabric Defect Detection and Classification Using Image Analysis. Textile Research $\quad$ Journal, $\quad 65(1), \quad$ 1-9. http://dx.doi.org/10.1177/004051759506500101

\section{Copyright Disclaimer}

Copyright for this article is retained by the author(s), with first publication rights granted to the journal.

This is an open-access article distributed under the terms and conditions of the Creative Commons Attribution license (http://creativecommons.org/licenses/by/3.0/). 